\title{
ANALISIS PENGENDALIAN INTERNAL COMMITTEE OF SPONSORING ORGANIZATIONS TERHADAP PIUTANG USAHA PADA CV. KOMBOS MANADO 1
}

\author{
Christian Jeanry Liho ${ }^{1}$, Sifrid Pangemanan ${ }^{2}$, Rudy Pusung ${ }^{3}$ \\ 1,2,3 Jurusan Akuntansi, Fakultas Ekonomi dan Bisnis, Universitas Sam Ratulangi, Jl. Kampus Bahu, Manado, \\ 95115, Indonesia \\ E-mail : christianliho@yahoo.com
}

\begin{abstract}
Accounts receivable is an element of current assets in the company's balance sheet arising from the sale of goods, services or lending to debtors whose payments are generally given within 30 days to 90 days. This research was conducted to analyze internal control committee of sponsoring organizations to accounts receivable at CV. Kombos Manado 1 and analyze the factors of delay in payment of accounts receivable on $C V$. Kombos Manado 1. The research method used is descriptive method and the type of research used is qualitative descriptive. The results obtained that the Internal Control Committee Of Sponsoring Organizations Against Accounts Receivable on CV. Kombos Manado 1 has been running quite well. Of the 5 (five) internal control components of the committee of sponsoring organizations, namely the control environment, risk assessment, control procedures, monitoring, information and communication, only a weakly categorized control environment. The obstacle faced by the receivable officer is the delay of payment of receivable from the customer. There are 2 (two) factors the customer is late to pay the receipt of the negligence of the company and negligence from the customer (insurance).

Keywords: Analysis, Internal Control, Accounts Receivable.
\end{abstract}

\section{PENDAHULUAN}

Ekonomi Indonesia saat ini lebih baik dibandingkan tahun-tahun sebelumnya. Ini bisa dilihat dari laju konsumsi, investasi, serta kondisi neraca perdagangan dan APBN. Adanya pertumbuhan ekonomi nasional, membuat persaingan di dalam dunia usaha menjadi lebih sulit. Persaingan yang ketat menunjukkan adanya perkembangan dan pertumbuhan dari usaha-usaha yang ada di Indonesia. Maka seluruh perusahaan yang ada di Indonesia harus mempersiapkan diri dengan sebaik-baiknya untuk meningkatkan kinerja perusahaan agar tetap bertahan. Setiap perusahaan yang didirikan tentu memiliki tujuan untuk memperoleh laba, akan tetapi tujuan perusahaan didirikan tidak hanya sampai pada seberapa banyak laba yang diperoleh oleh perusahaan, pendiri perusahaan tentu saat mendirikan sebuah perusahaan berharap agar perusahaan yang didirikan selain memperoleh laba yang tinggi juga ingin agar perusahaannya bisa tumbuh dan berkembang sehingga umur perusahaan panjang.

Dalam upaya mencapai tujuan utama, tiap perusahaan sudah sepatutnya memiliki suatu alat yang dapat dijadikan kontrol atas kinerja dan sistem yang berjalan didalamnya. Alat tersebut adalah pengendalian internal atau Internal Control. Suatu proses yang dipengaruhi oleh sumber daya manusia dan sistem teknologi informasi, yang di rancang untuk membantu organisasi mencapai suatu tujuan atau objektif tertentu merupakan definisi pengendalian internal dalam teori akuntansi dan organisasi. Pengendalian internal merupakan cara yang dilakukan manajemen perusahaan untuk mengurangi potensi timbulnya kecurangan yang mungkin terjadi dalam sistem yang ada di perusahaan. Pengendalian internal juga merupakan suatu cara untuk mengarahkan, mengawasi, dan mengukur sumber daya suatu organisasi. Pengendalian internal berperan penting untuk mencegah dan mendeteksi 
penggelapan (fraud) dan melindungi sumber daya organisasi baik yang berwujud (seperti mesin dan lahan) maupun yang tidak berwujud (seperti reputasi atau hak kekayaan intelektual seperti merek dagang). Seluruh komponen perusahaan harus bekerja sama agar target perusahaan dapat tercapai dengan baik, salah satu caranya adalah dengan membenahi terlebih dahulu pengendalian internal perusahaan. Jika tujuan pengendalian internal berhasil dicapai dengan baik, maka secara otomatis target perusahaan akan tercapai dengan baik pula.

Dalam neraca perusahaan terdapat unsur yang timbul akibat adanya penjualan barang, jasa atau pemberian kredit terhadap debitur yaitu aktiva lancar yang disebut piutang yang pembayarannya pada umumnya diberikan dalam kurun waktu 30 hari sampai dengan 90 hari. Dalam arti yang lebih luas, piutang didefenisikan sebagai tuntutan terhadap pihak lain yang berupa uang, barang atau jasa yang dijual secara kredit. Sedangkan pengertian piutang lebih sempit dalam akuntansi sebagai tuntutan pada pihak debitur yang diharapkan diselesaikan dengan penerimaan sejumlah uang tunai.

\section{TINJAUAN PUSTAKA}

\subsection{Akuntansi}

Willsson V, Freeman S dan Freeman J (2015:4) menyatakan bahwa akuntansi adalah proses pengumpulan, pengklasifikasian, pencatatan, pelaporan, penginterpretasian dan analisis dampak dari transaksi keuangan pada suatu bisnis atau organisasi untuk menyediakan informasi kepada pemilik manajemen dan pihak yang membutuhkan lainnya. Mardiasmo (2014:5) menyatakan fungsi akuntansi adalah berhubungan dengan pencatatan transaksitransaksi dalam suatu perusahaan atau suatu unit ekonomi yang lain, dan penyusunan laporan keuangan secara periodik dari catatan tersebut. .

\subsection{Akuntansi Keuangan}

Informasi keuangan pada suatu entitas dicatat, diklasifikasi, diringkas, diinterpretasikan, dan dikomunikasikan merupakan definisi akuntansi keuangan. Adapun pihak yang memerlukan informasi akuntansi terbagi ke dalam 2 (dua) jenis yaitu pihak internal dan pihak eksternal. Pengguna eksternal dari informasi akuntansi adalah investor, kreditor pelanggan dan pemerintah. Tujuan dari akuntansi keuangan adalah untuk menyediakan informasi yang relevan dan terkini untuk keperluan pengambilan keputusan pengguna diluar bisnis.

\subsection{Piutang}

Karamoy dan Nangoi (2014) menyatakan piutang merupakan komponen aktiva lancar yang penting dalam aktivitas ekonomi suatu perusahaan karena merupakan aktiva lancar perusahaan yang paling besar setelah kas. Piutang sendiri timbul dari penjualan barang ataupun jasa karena terdapat kebijakan secara kredit yaitu :

1. Pembeli membutuhkan barang dan jasa secara langsung, namun tidak bisa membayar secara langsung atau lebih menyukai untuk membayar secara kredit atau cicil.

2. Penjual dapat menjual lebih banyak dengan melakukan penjualan kredit dibandingkan dengan hanya melakukan penjualan tunai.

\subsection{Pengendalian Internal Berdasarkan Committee Of Sponsoring Organizations.}

Berbicara mengenai pengendalian internal atas piutang usaha, maka sesungguhnya yang menjadi pusat perhatian kita adalah bagaimana pengamanan yang efisien dan efektif dilakukan atas piutang usaha, baik dari segi pengamanan atas perolehan fisik kas, pemisahan tugas (termasuk masalah otoritas persetujuan kredit), sampai pada tersedianya data catatan akuntansi yang akurat. Beberapa ahli memiliki pendapat mengenai pengendalian internal perusahaan, salah satu diantaranya adalah Mulyadi (2016:129) yang menyatakan struktur organisasi, metode, dan ukuran-ukuran yang dikoordinasikan untuk menjaga aset organisasi, memeriksa ketelitian dan ketepatan atas data akuntansi, mendorong efisiensi dan mendorong dipatuhinya kebijakan manajemen termasuk dalam pengendalian internal. 
Pengertian pengendalian internal menurut Committee of Sponsoring Organizations (COSO) dalam Amin (2014:31) adalah sebagai berikut: "Pengendalian Internal adalah sebuah proses yang dilakukan oleh entitas dewan direksi, pihak manajemen, dan personel perusahaan lainnya, yang dirancang untuk memberikan keyakinan yang memadai tentang pencapaian tujuan organisasi dalam hal/kategori sebagai berikut:

1. Operasi Penggunaan sumber daya secara efektif dan efisien

2. Kepatuhan

Kepatuhan terhadap hukum dan peraturan

3. Pelaporan Keuangan

Penyusunan laporan keuangan yang dapat dipublikasikan dan terpercaya".

\subsubsection{Tujuan Pengendalian Internal}

Terdapat beberapa pendapat dari para ahli mengenai tujuan diadakannya pengendalian internal, salah satunya adalah Mulyadi (2016). Tujuan pokok pengendalian intern menurut Mulyadi (2016:129) adalah sebagai berikut:

1. Menjaga kekayaan organisasi,

2. Mengecek ketelitian dan keandalan data akuntansi,

3. Mendorong efisiensi, dan

4. Mendorong dipatuhinya kebijakan manajemen.

\subsubsection{Unsur-unsur Pengendalian Internal}

Terdapat beberapa unsur yang harus dipenuhi untuk dapat memperoleh suatu pengendalian internal yang memadai. Dalam bukunya, Mulyadi (2016:130) mengatakan bahwa unsur-unsur atau komponen yang ada dalam sistem pengendalian internal terdiri dari:

1. Struktur organisasi yang memisahkan tanggung jawab fungsional secara tegas.

2. Menyediakan perlindungan yang cukup atas kekayaan, kewajiban, pendapatan dan biaya dalam sistem wewenang dan prosedur pencatatan.

3. Praktik yang sehat dalam melaksanakan tugas dan fungsi setiap unit organisasi.

4. Karyawan yang mutunya sesuai dengan tanggung jawabnya.

5. Adanya sitem pengendalian intern sudah pasti harus diwujudkan dalam bentuk kegiatan-kegiatan konkret.

Committee of Sponsoring of Organization (COSO) dalam Internal Control - Integrated Framework (2013: 6-7) bahwa pengendalian internal memiliki lima komponen yang saling berhubungan, yaitu:

1. Lingkungan Pengendalian (Control Environment) Pentingnya pengendalian yang ada di organisasi meliputi sikap para manajemen dan karyawan

2. Penilaian Risiko (Risk Assestment)

Risiko yang dimiliki organisasi yaitu ada dalam suatu aktivitas, baik aktivitas yang berkaitan dengan bisnis maupun non bisnis.

3. Prosedur Pengendalian (Control Activities)

Untuk menjamin tercapainya tujuan perusahaan dan mencegah atau mendeteksi terjadinya ketidakberesan dan kesalahan perlu ditetapkan prosedur pengendalian dalam menstandarisasi kinerja.

4. Pemantauan (Monitoring)

Untuk menemukan kekurangan serta meningkatkan efektivitas pengendalian perlu dilakukan pemantauan pengendalian internal. Pengendalian internal dapat di monitor secara efektif melalui penilaian khusus atau sejalan dengan usaha manajemen.

5. Informasi dan Komunikasi (Information and Communication) 
Informasi dan komunikasi merupakan unsur-unsur yang penting dari pengendalian internal perusahaan. Manajemen perlu mengetahui tentang lingkungan pengendalian, penilaian risiko, prosedur pengendalian, dan pemantauan untuk dijadikan sebagai pedoman operasional dan menjamin ketaatan dengan pelaporan hukum serta peraturan-peraturan yang berlaku pada perusahaan.

\subsection{Penelitian terdahulu}

Penelitian terdahulu yang penulis jadikan sebagai bahan pertimbangan dalam melakukan penelitian di CV. Kombos Manado 1 adalah Penelitian yang dilakukan oleh Venny Karamoy dan Grace Bernadette Nangoi tahun 2014, tentang Analisis Piutang pada PT. SUCOFINDO (Persero) Cabang Manado, menunjukkan bahwa piutang yang telah jatuh tempo $\leq 90$ hari dan piutang yang berumur 91-360 hari dapat ditagih dengan baik. Sementara piutang yang berumur $>1$ tahun sebesar $55,4 \%$. diklasifikasikan sebagai piutang macet yang akan disisihkan menjadi piutang tak tertagih.

\section{METODE PENELITIAN}

\subsection{Jenis Penelitian}

Penelitian yang dilakukan merupakan Penelitian Deskriptif. Penelitian Deskriptif merupakan penelitian yang menjelaskan setiap data yang diperoleh, fenomena yang terjadi dan hasil penelitian di lapangan yang ditemukan, dalam bentuk kata-kata yang menceritakan, mengemukakan dan menggambarkan situasi tersebut yang memiliki makna sesuai dengan hasil penelitian yang dilakukan. Penelitian ini menggunakan data kualitatif sebagai dasar untuk menganalisis bagaimana pengendalian internal committee of sponsoring organizations terhadap piutang usaha pada CV. Kombos Manado 1.

\subsection{Waktu dan Tempat Penelitian}

Penelitian ini dilaksanakan pada CV. Kombos Manado 1 berlokasi di Jl. Raya Kombos Manado, kelurahan kombos timur, kecamatan singkil, kota Manado, Sulawesi Utara. Waktu penelitian dimulai dari bulan maret sampai dengan bulan april 2018.

\subsection{Metode Analisis}

Dasar dari penelitian ini adalah 5 (lima) komponen pengendalian internal committee of sponsoring organization yaitu lingkungan pengendalian, penilaian risiko, prosedur pengendalian, pemantauan, informasi dan komunikasi. Dari dasar ini, dilakukan wawancara dengan petugas piutang CV. Kombos Manado 1 kemudian dilihat dan dinilai apakah perusahaan menerapkan komponen pengendalian tersebut dan bagaimana pengelolaannya dan ditarik sebuah kesimpulan.

\section{HASIL ANALISIS DAN PEMBAHASAN}

4.1 Hasil analisis

\subsubsection{Komponen Pengendalian Internal Committee Of Sponsoring Organizations} Terhadap Piutang Usaha Pada CV. Kombos Manado 1

CV. Kombos Manado 1 dalam menjalankan usahanya memberikan kemudahan kepada pelanggan untuk membayar biaya perbaikan kendaraan secara kredit. Namun hal ini hanya diperuntukkan untuk pelanggan yang berbentuk lembaga atau badan yang melakukan PKS (Perjanjian Kerja Sama) dengan CV. Kombos Manado 1 seperti asuransi, dealer dan badan/lembaga lainnya. Total pelanggan yang melakukan PKS dengan CV. Kombos Manado 1 sebanyak 15 pelanggan. Jadi pelanggan yang menerima kredit adalah orang yang berada dalam naungan sebuah asuransi atau sebuah lembaga.

Adapun komponen pengendalian internal committee of sponsoring organizations terhadap piutang usaha pada CV. Kombos Manado 1 adalah sebagai berikut:

\section{Lingkungan Pengendalian (Control Environment)}


CV. Kombos Manado 1 menjunjung tinggi integritas dan kompetensi yang artinya setiap karyawan harus memiliki kemampuan dan bertanggung jawab dibidangnya masing-masing. Pekerjaan yang dilakukan oleh karyawan disetiap divisi saling berhubungan satu dengan yang lain.

Berikut adalah pengelolaan piutang pada CV. Kombos Manado 1:

a. Pelanggan datang ke CV. Kombos Manado 1

Pelanggan membawa kendaraan yang akan di perbaiki dan mengajukan kredit dan dilihat bagaimana kondisi kendaraan dan perusahaan akan melakukan estimasi harga dari kendaraan yang akan diperbaiki. Setelah pelanggan mendapatkan estimasi harga, kendaraan harus dibawa pulang kembali karna harga yang sudah diestimasi sebelumnya harus dikonfimasi terlebih dahulu kepada lembaga atau badan atau asuransi yang melakukan PKS dengan CV. Kombos Manado 1. Service Advisor (MRS) akan menghubungi pelanggan untuk melakukan konfirmasi perbaikan kendaraan jika estimasi harga sudah disepakati.

b. Menerima nomor booking dan konsultasi

Pelanggan yang telah dihubungi sebelumnya akan datang ke CV. Kombos Manado 1 membawa kendaraan yang akan diperbaiki dan menerima nomor booking serta melakukan konsultasi dengan Service Advisor.

c. Proses Pengerjaan Mekanik

Kendaraan yang sudah diterima oleh $S A$ akan lansung diserahkan kepada mekanik untuk bisa diperbaiki. Mekanik akan mengisi formulir tentang bahan-bahan yang akan digunakan untuk perbaikan kendaraan pelanggan.

d. Pembuatan Kwitansi

Formulir yang sudah diisi oleh mekanik akan diberikan kepada karyawan pembuat kwitansi untuk diinput ke DMS (Dealer Manager Service) dan dibuatkan kwitansi.

e. Kasir

Kwitansi yang telah dibuat dan formulir yang telah diisi oleh mekanik akan diberikan kepada bagian kasir untuk diproses menjadi Service Invoice (3 lembar) dan pelanggan bisa melakukan pembayaran. Untuk pembayaran secara kredit maka SI yang sudah dibuat oleh bagian kasir akan diserahkan ke bagian piutang untuk disimpan dan dijadikan bukti bahwa belum terjadi pembayaran.

f. Penyerahan Kendaraan

Pelanggan yang menerima kredit dan sudah menerima SI dari kasir akan menunggu dan nantinya akan menerima kendaraan yang sudah diperbaiki. Selanjutnya petugas piutang akan mengingatkan pelanggan untuk melakukan pembayaran (piutang) pada tanggal yang sudah disepakati (60-90 hari setelah tanggal transaksi).

g. Penagihan Piutang

Setelah pelanggan merima kembali kendaraan yang sudah diperbaiki maka dalam kurun waktu 60-90 hari dari tanggal transaksi, pelanggan harus membayar tagihan (piutang) dari perbaikan kendaraan tersebut. Adapun proses penagihan dari piutang adalah sebagai berikut:

1. SI yang disimpan oleh petugas piutang harus dilengkapi dengan dokumendokumen seperti:

a. Estimasi biaya perbaikan asli

b. S. P. K (Perjanjian Kerja Sama)

c. Foto kerusakan kendaraan 

d. Kertas fisik nomor rangka dan nomor mesin
e. Fotocopy KTP
f. Fotocopy STNK/SIM
g. Foto Epoxy dan foto nomor polis
h. Surat pernyataan puas
i. Faktur pajak
j. Formulir klaim
k. Fotocopy polis asuransi

2. Setelah lengkap, dokumen dikirim kepada pelanggan untuk pelanggan bisa membayar. Bila tidak lengkap dokumen akan dikembalikan dan pelanggan belum bisa membayar.

3. Waktu pembayaran adalah 60-90 hari dari tanggal transaksi. Pembayaran dilakukan via transfer rekening CV. Kombos Manado 1.

4. Jika dokumen lengkap dan sudah dikirim kepada pelanggan tapi pelanggan tidak melakukan pembayaran sampai kurun waktu yang ditentukan maka petugas piutang akan melakukan hal berikut ini:

a. Petugas piutang akan mengingatkan pelanggan via email untuk membayar piutang berdasarkan outstanding atau data piutang yang ada di DMS.

b. Jika email yang dikirim tidak mendapat balasan atau masih belum membayar, maka petugas piutang akan menghubungi pelanggan via telepon.

c. Jika sudah ditelepon dan pelanggan masih belum membayar, maka petugas piutang bersama dengan kepala HRD atau service manager akan melakukan kunjungan dirumah pelanggan dan menentukan estimasi tanggal pembayaran. Biasanya setelah menempuh beberapa tahap diatas, pelanggan akan melakukan pembayaran.

2. Penilaian Risiko (Risk Assestment)

Penilaian risiko adalah tindakan yang dilakukan oleh CV. Kombos Manado 1 sebelum melakukan kerjasama dengan pelanggan. Perusahaan akan melakukan crosscheck dengan bengkel-bengkel lain untuk mencari tahu sifat dari pelanggan yang mengajukan kredit misalnya bagaimana pembayarannya, tepat waktu atau tidak, dan lain sebagainya. Setelah mendapatkan informasi pelanggan dan jika perusahaan merasa pelanggan tersebut layak untuk diberikan kredit maka perusahaan akan melakukan PKS (Perjanjian Kerja Sama) dengan pelanggan tersebut. Tapi jika tidak, maka perusahaan akan menolak kredit yang diajukan oleh pelanggan.

3. Prosedur Pengendalian (Control Activities)

Prosedur pengendalian adalah proses yang dilakukan sebelum, sementara dan sesudah melakukan PKS (Perjanjian Kerja Sama) dengan pelanggan. Perusahan harus mempersiapkan hal-hal berikut ini:

a. Sebelum terjadi PKS, CV. Kombos Manado 1 harus memiliki persetujuan dari kantor pusat (HO).

b. Aktivitas tanggung jawab dan kewenangan dilakukan oleh bagian keuangan mengetahui kabag keuangan dan service manager.

c. Petugas piutang harus menyimpan dokumen piutang seperti dokumen PKS, bukti transfer dan rekening koran CV. Kombos Manado 1.

d. Petugas piutang harus melakukan rekonsiliasi transaksi piutang setiap pelanggan.

e. Petugas yang mengelolah piutang adalah karyawan yang kompeten. 
4. Pemantauan (Monitoring)

Pemantauan atau pengawasan adalah kegiatan yang dilakukan untuk menemukan kekurangan dan keefektifan dari pengendalian yang dilakukan. Untuk pengawasan didalam CV. Kombos Manado 1 dilakukan oleh kabag keuangan CV. Kombos Manado 1, dan pengawasan dari pusat (HO) dilakukan oleh Manajer Keuangan (HO)

5. Informasi dan Komunikasi (Information and Communication)

Informasi piutang adalah informasi yang diterima dari seluruh bagian yang mengurus segala sesuatu mengenai piutang. Karena pekerjaan yang dilakukan oleh karyawan CV. Kombos Manado 1 saling berhubungan maka secara tidak langsung piutang dikelola oleh setiap bagian dalam perusahaan.

\subsubsection{Faktor-faktor Keterlambatan Pembayaran Piutang Usaha Pada CV. Kombos Manado 1}

Hambatan yang dihadapi oleh CV. Kombos Manado 1 khususnya petugas piutang adalah keterlambatan pembayaran piutang dari pelanggan. Berdasarkan wawancara dan penelitian yang dilakukan, ada 2 (dua) faktor mengapa pelanggan terlambat membayar piutangnya yaitu:

1. Kelalaian dari pihak perusahaan

Petugas piutang tidak terdiri dari satu orang saja, tetapi beberapa orang. Sayangnya para petugas yang lain tidak menjalankan tugasnya dengan teliti sehingga didapati banyak kesalahan dalam pengumpulan dokumen pelengkap.

2. Kelalaian dari pihak pelanggan (asuransi).

Pelanggan terlambat membayar bukan hanya dikarenakan kelalaian perusahaan tetapi karena pelanggan juga gagal melaksanakan kewajibannya. Hal ini disebabkan tidak adanya persiapan dari pelanggan untuk membayar piutangnya..

\subsection{Pembahasan}

\subsubsection{Analisis Pengendalian Internal Committee Of Sponsoing Organizations Terhadap} Piutang Usaha Pada CV. Kombos Manado 1

Berikut ini adalah tabel pengendalian internal dan tabel kuat dan lemah untuk menilai komponen pengendalian internal committee of sponsoring organizations CV. Kombos Manado 1.

\section{Tabel 4.2 Kategori kuat dan lemah}

\begin{tabular}{|l|l|l|l|}
\hline \multicolumn{2}{|l|}{ Kategori } \\
\hline \multirow{3}{*}{ Lemah } & Tidak Teliti & Teliti \\
\cline { 2 - 2 } & Tidak Tegas & Tegas \\
\cline { 2 - 2 } & Sikap Lemah & Kuat & Cakap \\
\cline { 2 - 2 } & $\begin{array}{l}\text { Tidak Bertanggung } \\
\text { Jawab }\end{array}$ & $\begin{array}{l}\text { Bertanggung } \\
\text { Jawab }\end{array}$ \\
\hline
\end{tabular}

Tabel 4.3 Pengendalian Internal Berdasarkan Committee Of Sponsoring Organizations Terhadap PiutangUsaha Pada CV. Kombos Manado 1.

\begin{tabular}{|c|l|c|l|}
\hline Nomor & $\begin{array}{l}\text { Komponen Pengendalian Internal } \\
\text { COSO }\end{array}$ & Kuat / Lemah & \multicolumn{1}{|c|}{$\begin{array}{c}\text { Pengendalian Internal } \\
\text { Piutang Perusahaan }\end{array}$} \\
\hline 1. & $\begin{array}{l}\text { Lingkungan Pengendalian (Control } \\
\text { Environment). } \\
\text { Mencakup sikap para manajemen } \\
\text { dan karyawan terhadap pentingnya } \\
\text { pengendalian yang ada di organisasi } \\
\text { tersebut. }\end{array}$ & $\begin{array}{l}\text { Lemah } \\
\text { (Tidak Teliti) }\end{array}$ & $\begin{array}{l}\text { Terdapat struktur organisasi } \\
\text { yang jelas serta ada pembagian } \\
\text { tugas, wewenang dan } \\
\text { tanggung jawab } \\
\text { ketenagakerjaan. Hanya saja } \\
\text { karna kurangnya karyawan, } \\
\text { ada petugas piutang yang tidak } \\
\text { teliti dalam melaksanakan }\end{array}$ \\
\hline
\end{tabular}




\begin{tabular}{|c|c|c|c|}
\hline Nomor & $\begin{array}{c}\text { Komponen Pengendalian Internal } \\
\text { COSO }\end{array}$ & Kuat / Lemah & $\begin{array}{c}\text { Pengendalian Internal } \\
\text { Piutang Perusahaan }\end{array}$ \\
\hline & & & $\begin{array}{l}\text { tugasnya karna harus } \\
\text { melakukan lebih dari satu } \\
\text { pekerjaan sehingga menjadi } \\
\text { salah satu penyebab dalam } \\
\text { keterlambatan pembayaran } \\
\text { piutang dari pelanggan. }\end{array}$ \\
\hline 2. & $\begin{array}{l}\text { Penilaian Risiko } \\
\text { (Risk Assestment). } \\
\text { Risiko yang dimiliki organisasi yaitu } \\
\text { ada dalam suatu aktivitas, baik } \\
\text { aktivitas yang berkaitan dengan } \\
\text { bisnis maupun non bisnis. }\end{array}$ & $\begin{array}{c}\text { Kuat } \\
\text { (Teliti, Tegas, } \\
\text { Cakap, } \\
\text { Bertanggung } \\
\text { jawab) }\end{array}$ & $\begin{array}{l}\text { Sebelum perusahaan } \\
\text { melakukan perjanjian kerja } \\
\text { sama, perusahaan akan } \\
\text { melakukan crosscheck dengan } \\
\text { bengkel-bengkel lain terlebih } \\
\text { dahulu untuk mencari tahu } \\
\text { sifat dari pelanggan yang } \\
\text { mengajukan kredit. }\end{array}$ \\
\hline 3. & $\begin{array}{l}\text { Prosedur Pengendalian } \\
\text { (Control Activities). } \\
\text { Untuk menjamin tercapainya tujuan } \\
\text { perusahaan dan mencegah atau } \\
\text { mendeteksi terjadinya } \\
\text { ketidakberesan dan kesalahan perlu } \\
\text { ditetapkan prosedur pengendalian } \\
\text { dalam menstandarisasi kinerja. }\end{array}$ & $\begin{array}{c}\text { Kuat } \\
\text { (Teliti, Tegas, } \\
\text { Cakap, } \\
\text { Bertanggung } \\
\text { jawab) }\end{array}$ & $\begin{array}{l}\text { Perusahaan } \\
\text { memperhatikan proses yang } \\
\text { dilakukan sebelum sampai } \\
\text { sesudah menjalin Perjanjian } \\
\text { Kerja Sama, juga } \\
\text { memperhatikan aktifitas dan } \\
\text { tanggung jawab dari setiap } \\
\text { karyawan yang bertugas } \\
\text { mengelola piutang. Sehingga } \\
\text { dapat mengetahui dengan pasti } \\
\text { masalah atau kesalahan dalam } \\
\text { pengelolaan piutang. }\end{array}$ \\
\hline 4. & \begin{tabular}{lrr} 
Pemantauan & \multicolumn{2}{c}{ (Monitoring). } \\
Pemantauan & terhadap & sistem \\
pengendalian internal akan & akan \\
menemukan kekurangan serta \\
meningkatkan \\
pengendalian. Pengendalian internal \\
dapat di monitor secara efektif \\
melalui penilaian khusus atau \\
sejalan dengan usaha manajemen.
\end{tabular} & $\begin{array}{c}\text { Kuat } \\
\text { (Teliti, Tegas, } \\
\text { Cakap, } \\
\text { Bertanggung } \\
\text { jawab) }\end{array}$ & $\begin{array}{l}\text { Pengawasan dan pemantauan } \\
\text { dilakukan langsung oleh } \\
\text { kepala bagian keuangan dan } \\
\text { manajer keuangan terhadap } \\
\text { karyawan petugas piutang. }\end{array}$ \\
\hline 5. & $\begin{array}{l}\text { Informasi dan } \\
\text { (Information and Communication). } \\
\text { Informasi dan komunikasi } \\
\text { merupakan unsur-unsur yang } \\
\text { penting dari pengendalian internal } \\
\text { perusahaan. Manajemen perlu } \\
\text { mengetahui tentang lingkungan } \\
\text { pengendalian, penilaian risiko, } \\
\text { prosedur pengendalian, dan } \\
\text { pemantauan untuk dijadikan sebagai } \\
\text { pedoman operasional dan menjamin } \\
\text { ketaatan dengan pelaporan hukum } \\
\text { serta peraturan-peraturan yang } \\
\text { berlaku pada perusahaan. }\end{array}$ & $\begin{array}{c}\text { Kuat } \\
\text { (Teliti, Tegas, } \\
\text { Cakap, } \\
\text { Bertanggung } \\
\text { jawab) }\end{array}$ & 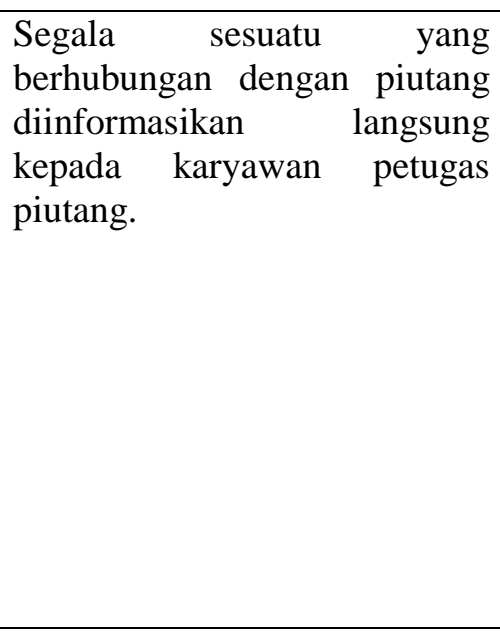 \\
\hline
\end{tabular}


Dari 5 (lima) komponen pengendalian internal committee of sponsoring organizations yaitu lingkungan pengendalian, penilaian risiko, prosedur pengendalian, pemantauan, informasi dan komunikasi, hanya lingkungan pengendalian yang dikategorikan lemah karena berhubungan dengan sumber daya manusia yang terbatas serta tidak adanya SOP (Standard Operating Procedur) untuk setiap petugas piutang. Dalam melaksanakan pekerjaan, satu orang petugas piutang harus melakukan lebih dari satu pekerjaan sehingga sangat memungkinkan adanya ketidaktelitian terhadap pekerjaan yang dilakukan.

\subsubsection{Analisis Faktor-faktor Keterlambatan Pembayaran Piutang Usaha Pada CV. Kombos Manado 1}

Berdasarkan wawancara yang telah dilakukan dengan responden yaitu petugas piutang $\mathrm{CV}$. Kombos Manado 1, ada 2 (dua) faktor yang mempengaruhi keterlambatan pembayaran piutang usaha, yaitu:

1. Kelalaian dari perusahaan (sumber daya manusia).

Untuk pelanggan bisa membayar tagihannya, pelanggan harus menerima terlebih dahulu tagihan serta dokumen pelengkap yang dikirim perusahaan kepada pelanggan. Namun dokumen pelengkap yang dikirimkan kepada pelanggan sering dikembalikan lagi kepada perusahaan karena dokumen-dokumen tersebut tidak lengkap. Alasan dokumennya tidak lengkap karna kurangnya karyawan dalam pengelolaan piutang. Di CV. Kombos Manado 1, satu orang karyawan tidak melakukan satu pekerjaan, tapi beberapa pekerjaan (merangkap). Contohnya, petugas yang menangani perbaikan body (pelanggan kredit) harus mengurus juga dokumen yang akan dikirim sebagai bukti tagihan. Pada kenyataannya faktor usia juga menjadi salah satu alasan dokumen yang harus dikirim tidak lengkap. Petugas yang mengurus dokumen-dokumen tersebut sudah berumur (tua) sehingga memungkinkan ada dokumen yang tercecer atau tidak lengkap.

2. Kelalaian Pelanggan (Asuransi)

Ketika pelanggan sudah menerima tagihan dan dokumen pelengkap namun tidak dikembalikan kepada CV. Kombos Manado 1 dan pelanggan belum juga membayar, berarti kelalaian ada disisi pelanggan. Pelanggan (asuransi) memberikan alasan bahwa tagihan yang diterima harus dikirim kekantor pusat, menunggu antrian untuk uang bisa dicairkan, atau masih menunggu dana, ada juga yang beralasan bahwa karyawan yang menangani penerimaan tagihan dokumen sedang tidak masuk, atau resign dari pekerjaan sehingga pembayaran tertunda.

\section{KESIMPULAN DAN SARAN}

\subsection{Kesimpulan}

Berdasarkan hasil penelitian dan pembahasan yang telah di jelaskan sebelumnya maka dapat diambil kesimpulan bahwa:

1. Pengendalian internal committee of sponsoring organizations terhadap piutang usaha pada CV. Kombos Manado 1 sudah berjalan cukup baik. 5 (lima) komponen pengendalian internal committee of sponsoring organizations yaitu lingkungan pengendalian, penilaian risiko, prosedur pengendalian, pemantauan, informasi dan komunikasi telah diterapkan perusahaan, hanya saja untuk lingkungan pengendalian masih dikategorikan lemah.

2. Keterlambatan pembayaran piutang usaha disebabkan oleh kurangnya karyawan (sumber daya manusia) yang mengelola piutang, khususnya pengelola dokumen pelengkap tagihan piutang usaha $\mathrm{CV}$. Kombos Manado 1 dan kelalaian pelanggan, dimana tagihan yang diterima pelanggan harus diproses terlebih dahulu, dikirim kekantor pusat, menunggu antrian untuk uang bisa dicairkan, atau karyawan yang 
menangani penerimaan tagihan dokumen sedang tidak masuk, atau resign dari

\subsection{Saran}

pekerjaan sehingga pembayaran tertunda.

Saran yang diberikan untuk CV. Kombos Manado 1 adalah:

1. CV. Kombos Manado 1 harus menambah karyawan dibagian keuangan (piutang) agar pengelolaan piutang dokumen pelengkap dapat berjalan lebih baik.

2. CV. Kombos Manado 1 harus lebih menyesuaikan keahlian karyawan dengan pekerjaan yang akan dilakukan.

3. CV. Kombos Manado 1 harus menetapkan secara resmi SOP pengelolaan piutang usaha.

\section{DAFTAR PUSTAKA}

Amin, W. Tunggal. 2014. Konsep dan Studi Kasus Auditing. Harvarindo. Jakarta.

Banteng, D. Astri. 2013. Analisis Pengakuan Piutang Tak Tertagih dan Penyajian Laporan Keuangan pada PT. Bank Sulut. Skripsi. Universitas Samratulangi. Manado.

Committee of Sponsoring Organizations of the Tradeway Commission (COSO). 2013. Internal Control - Integrated Framework.

Dunia, A. Firdaus. 2013. Pengantar Akuntansi. Edisi 4. Lembaga Penerbit Fakultas Ekonomi Universitas Indonesia. Jakarta.

Hamel, Gary. 2013. Evaluasi Sistem Pengendalian Intern Terhadap Piutang pada PT. Nusantara Surya Sakti. Jurnal EMBA Universitas Samratulangi Manado.

Hery. 2013. Akuntansi Dasar 1 dan 2. PT. Gramedia Widiasarana Indonesia. Jakarta.

J, Jerry., Weygandt., Paul, D. Kimmel., and Donald, E. Kieso. 2013. Financial Accounting. IFRS Edition. John Wiley \& Sons. New Jersey.

Karamoy, Venny., dan Nangoi, Grace. 2014. Analisis Piutang Pada PT. SUCOFINDO (Persero) Cabang Manado. Jurnal EMBA Universitas Samratulangi Manado.

Kennedy, M. Horace. 2014. Accounts receivable management and financial performance of manufacturing firms in Nakuru County. Thesis. University Of Nairobi. Kenya.

Mardiasmo. 2014. Akuntansi Keuangan Dasar. Edisi 3. BPFE. Yogyakarta.

Mulyadi. 2016. Sistem Akuntansi. Salemba Empat. Jakarta.

Wilsson, V., Freeman, S., and Freeman, J. 2015. Accounting : a Practical approach. Pearson Higher Education AU. Australia. 